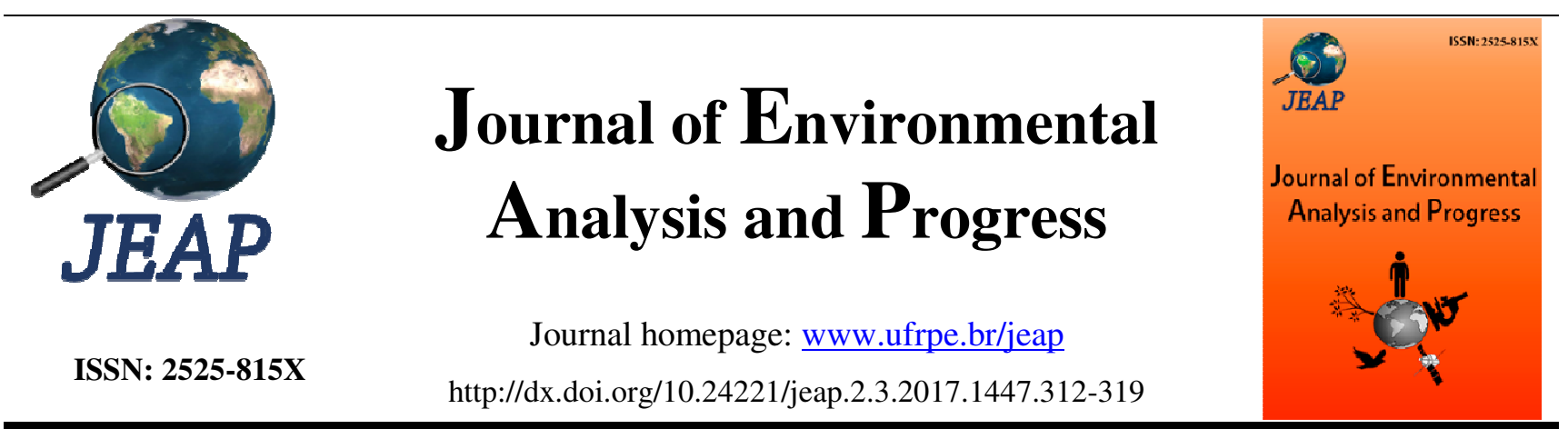

\title{
Monitoramento e análise da vegetação de manguezal no litoral sul de Alagoas
}

\section{Monitoring and analysis of mangrove vegetation on the south coast of Alagoas}

\author{
Lidiane Matias ${ }^{\mathrm{a}}$, Milena Dutra da Silva ${ }^{\mathrm{a}}$ \\ ${ }^{a}$ Universidade Federal de Alagoas-UFAL, Campus Arapiraca-Unidade Penedo, Avenida Beira Rio, Penedo, Alagoas. \\ CEP: 57200-000. E-mail: lidimatias038@gmail.com; milena.silva@ penedo.ufal.br.
}

\begin{tabular}{l}
\hline A R T I C L E I N F O \\
\hline Recebido 28 Jun 2017 \\
Aceito 15 Jul 2017 \\
Publicado 31 Jul 2017
\end{tabular}

Publicado 31 Jul 2017

\begin{abstract}
A B S T R A C T
The Mangrove is a coastal ecosystem of transition between terrestrial and marine environments, typical of tropical and subtropical regions subject to tidal flood; this environment presents specific characteristics with much organic matter and little oxygen, composed of a diversity of adapted special. Although considered a permanent preservation area, this ecosystem has over the years been the target of major impacts, most of them caused by anthropic actions, resulting from deforestation, the implantation of agriculture and pollution. Also, the disorderly growth of urban expansion and activities Tourism, with the inappropriate use, provoked damages in this ecosystem. Considering the analysis of the landscape and GIS (Geographic Information System) techniques, the study aimed to diagnose the spatial-temporal dynamics of the mangrove areas of the southern coast of Alagoas to identify areas with environmental recovery framework. It was carried out mapping through satellite images from Google Earth software corresponding the decades from 2004 to 2016 and made thematic maps using Quantum GIS software. Comparative analyses, through the interpretation of the maps and calculations of the areas, it was possible to diagnose that most of the municipalities presented a significant expansion of the mangrove area. Seemingly, this expansion is related to the extended period of drought in this region during the year and consequent decrease of the fresh water flow and increase of saline water entering the estuaries favoring the development of this vegetation.
\end{abstract}

Keywords: Comparative analysis, fragmentation, recovery.

\section{R E S U M O}

O Manguezal é um ecossistema costeiro de transição entre ambientes terrestre e marinho, típico de regiões tropicais e subtropicais sujeito a inundação de marés; este ambiente apresenta características especificas com muita matéria orgânica e pouco oxigênio, composto de uma diversidade de especiais adaptadas. Embora seja considerado áreas de preservação permanente este ecossistema vem ao longo dos anos sendo alvos de grandes impactos, estes na grande maioria causados por ações antrópicas, decorrentes de desmatamentos, implantação de agricultura e poluição. Adicionalmente, o crescimento desordenado da expansão urbana e das atividades turísticas, com o uso inadequado, provoca prejuízos a este ecossistema. Considerando as análises da paisagem e técnicas de SIG (Sistema de Informação Geográficas), o estudo objetivou: diagnosticar a dinâmica espaço-temporal das áreas de mangue do litoral Sul de Alagoas para identificar áreas que exibiram recuperação ambiental. Mapeamentos foram realizados através de imagens de satélites obtidas com o Google Earth, correspondente às décadas de 2004 a 2016, e elaborados mapas temáticos no Quantum GIS. Análises comparativas, através da interpretação dos mapas e cálculos das áreas, permitiram diagnosticar que a maioria dos municípios apresentaram uma expansão significativa da área de mangue. 
Aparentemente, essa expansão está relacionada ao longo período de seca nessa região durante o ano e consequente diminuição do fluxo de água doce e aumento da entrada de águas salinas nos estuários, favorecendo o desenvolvimento dessa vegetação.

Palavras-Chave: Análises comparativas, fragmentação, recuperação.

\section{Introdução}

O Manguezal é um ecossistema costeiro, típico de regiões tropicais e subtropicais, que desempenha diversas funções ecológicas, além de interesse econômico.

Esse ecossistema apresenta como característica uma alta salinidade, solos lamosos e rico em matéria orgânica, frequentemente submersos pelas marés, apresentado pouco oxigênio (Novelly, 1995). Tem importante papel ecológico conferindo abrigo e alimento para muitas espécies durante algum estágio da vida.

Esse ecossistema é caracterizado pela diversidade de espécies arbóreas e arbustivas, adaptadas a viver sob condições de pouco oxigênio, e frequentemente submetido a inundação de marés.

O manguezal ao longo dos anos vem sendo alvo de grandes impactos decorrentes de ações antrópicas, além dos fenômenos naturais. Segundo Quiñones (2000), os fenômenos naturais que afetam o manguezal são de baixa ou média densidade, afetando-o temporariamente, tornando quase sempre possível o restabelecimento da estrutura anterior. Os impactos ambientais de origem antrópicas prejudicam a estrutura e qualidade do manguezal por um longo tempo, causando, sob condições extremas, a morte de diversos organismos. Entre os impactos ambientais de origem antrópica destacam-se a extração desordenada de madeira, aterros, lixo, e desmatamento para atendimento a demanda de solo desnudo para agricultura e, ou, expansão urbana.

No Brasil, os manguezais se estabelecem desde a foz do rio Oiapoque, no Estado do Amapá até o Estado de Santa Catarina, onde predominam três espécies vegetais: Rhizophora mangle L. (mangue vermelho) a Laguncularia racemosa $\mathrm{L}$. (mangue branco) e Avicennia schaueriana Stapft \& Leechm. Conforme Santos (2009), a baixa diversidade florística do manguezal se deve às condições abióticas às quais o ecossistema está submetido, pois poucas espécies apresentam adaptações para sobreviver em um ambiente com essas características.

Ao longo do litoral de Alagoas, a presença de manguezais nos estuários é marcante, sendo reflexo de uma costa com influência de marés (Araújo et al., 2000). Conforme Oliveira \& Cunha (2007), "os manguezais protegem a linha da costa e as margens dos estuários contra erosão e enchentes, diminuindo a força das águas; filtram os poluentes, reduzindo a contaminação das praias".

Além da grande importância para o meio ambiente, o manguezal desempenha funções econômicas para muitas comunidades ribeirinhas, que retiram desse ambiente o sustento para as suas famílias, com a extração e venda de peixes, moluscos e crustáceos. Apesar disso, esse ecossistema continua sendo alvo de impactos que causam destruição total ou parcial de sua área por meio de ações como a exploração desordenada de sua fauna e flora. De acordo com Correia \& Sovierzoski (2008), no litoral de Alagoas, a degradação desse ecossistema está diretamente relacionada à ampliação da rede hoteleira e às atividades turísticas, que cresceram muito na região, além da grande expansão da monocultura de cana-de-açúcar e coco.

Diante disso, é fundamental desenvolver ações em busca de meios de conservação desse ecossistema, visto que os manguezais são considerados áreas de preservação permanente, de acordo com a Lei Federal no 12.651/2012 (Código Florestal), com limites de uso. Entretanto, em muitos casos, essa lei não é cumprida, e, em consequência disso, decorre a destruição do ecossistema. Diante do exposto, se fazem necessários estudos de monitoramento dessas áreas, visando mapear e realizar análises temporais do manguezal, propiciando a geração de informações para acompanhar seu desenvolvimento.

A utilização de geotecnologias vem ganhando espaço como ferramenta de monitoramento de áreas. Leite et al. (2012) afirmam que os métodos e técnicas de geoprocessamento e sensoriamento remoto permitem monitorar os problemas de degradação ambiental, pois analisam os fatores existentes na paisagem e suas transformações. Ressalta-se que, nesse sentido, o geoprocessamento e sensoriamento remoto contribui para a fiscalização de áreas de mangue e proposição de políticas públicas com fins de conservação e preservação do ecossistema.

Conforme Florenzano (2002), o ecossistema manguezal é facilmente destacado em imagens de satélites por sua forma irregular, cor mais escura que a dos demais biomas e tipos de vegetação, o que decorre da influência da água existente nesses ambientes e da sua localização 
litorânea, ao longo da zona costeira. Assim, a partir do uso e interpretação de imagens de satélites de diferentes anos, trabalhadas em Sistema de Informação Geográfica (SIG), é possível identificar, calcular e monitorar a dinâmica espaço-temporal de áreas com mangue. A análise da dinâmica da paisagem permite identificar áreas de mangue que passaram por transformações, devido a desmatamentos, ocupação urbana, entre outros fatores, quer de origem antrópica, quer de origem natural.

Diante do exposto, e frente a carência de investigações relacionadas ao monitoramento dessas áreas no Litoral Sul do Estado de Alagoas, o presente estudo teve por objetivo realizar uma análise multitemporal da vegetação de mangue, no período de 2004 a 2016, visando diagnosticar as áreas que apresentam maior fragilidade ambiental, bem como aquelas que apresentaram recuperação.

\section{Material e Métodos}

O litoral de Alagoas apresenta uma zona costeira de, aproximadamente, $230 \mathrm{~km} \mathrm{de}$ extensão. A área selecionada para o estudo compreende toda aquela recoberta por vegetação do ecossistema manguezal, no litoral sul, correspondente aos Municípios de Roteiro, Jequiá da Praia, Coruripe, Feliz Deserto e Piaçabuçu (Figura 1). A área de estudo limita-se, ao norte, pelo Município de Barra de São Miguel e, ao sul, pela foz do rio São Francisco, em Piaçabuçu, o qual faz divisa com o estado de Sergipe.

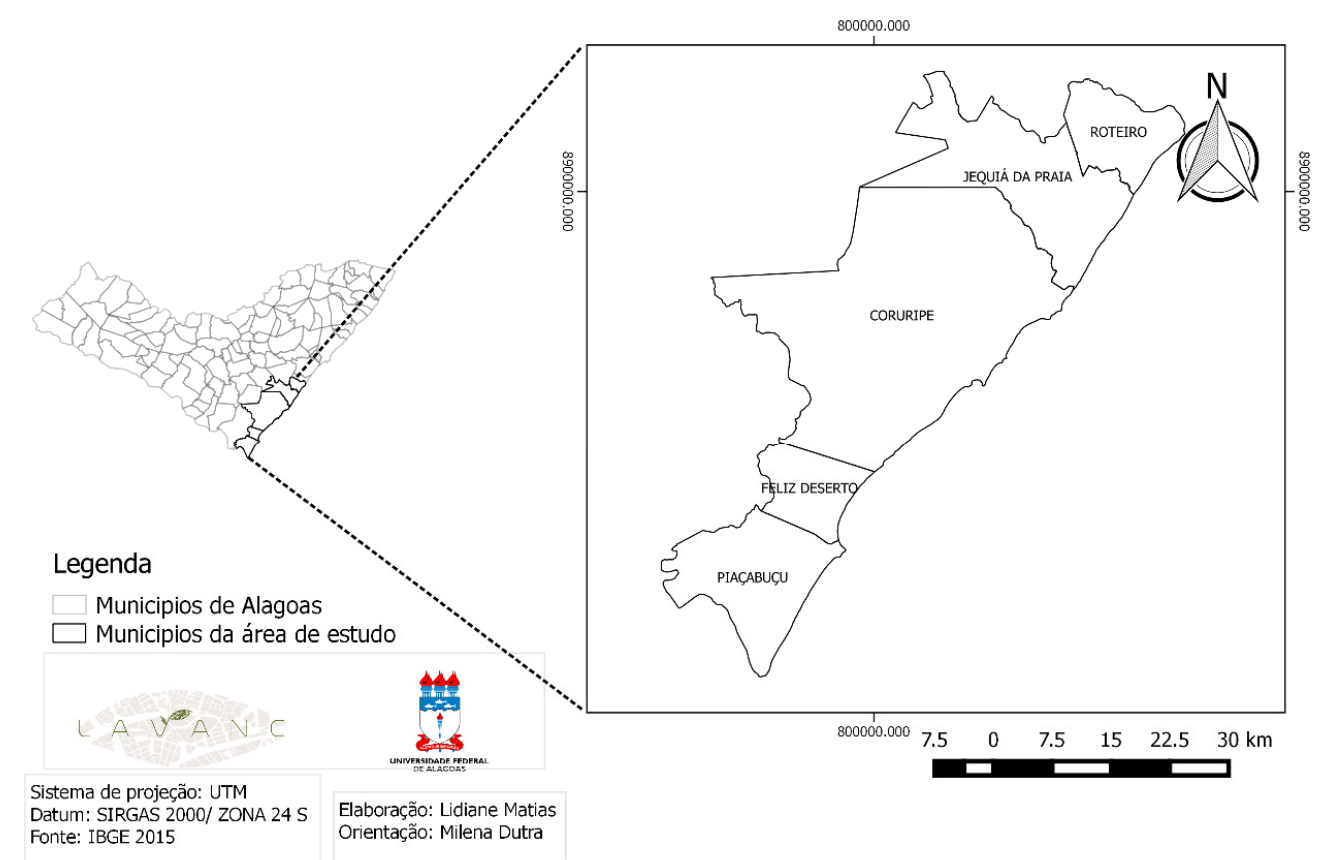

Figura 1. Localização dos municípios do litoral sul do estado de Alagoas, Brasil.

Neste estudo não foi possível realizar as análises comparativas das áreas de mangue do município de Feliz Deserto, devido à alta cobertura de nuvens nas imagens de satélite sobre as áreas do município. Em tempo, informamos que uma breve fotointerpretação dessas imagens, considerando a baixa visibilidade, indica um baixo percentual de mangue no município.

Foram realizados mapeamentos através de imagens de satélites disponíveis no software de visualização gratuita Google Earth, viabilizando análises comparativas de toda cobertura de mangue dos Municípios de Roteiro, Jequiá da Praia, Coruripe e Piaçabuçu, em um intervalo espaço-temporal de 10 anos, correspondendo às décadas de 2000 (imagem de satélite de dezembro de 2004 e setembro de 2006) e 2010 (imagem de satélite de agosto de 2016).
Para o desenvolvimento da pesquisa e análise temporal foi utilizado o software livre e gratuito Quantum Gis, no qual foram realizadas as análises das imagens a partir de dados vetoriais unidos em camada única.

As áreas diagnosticadas recuperadas correspondem às manchas da vegetação de mangue, onde foi possível constatar acréscimo ao longo dos anos.

Ao analisar a vegetação de mangue do litoral de Alagoas, observou-se que os municípios de Roteiro, Jequiá da Praia e Piaçabuçu apresentaram aumento de cobertura vegetal, no período de 2004 a 2016, principalmente, em áreas próximas as margens de lagoas e rios. No município de Coruripe, para o mesmo período, houve uma redução de, aproximadamente, $11 \%$ da área de mangue, dadas, sobretudo, nas regiões 
próximas as áreas urbanas. Em uma análise comparativa da paisagem, entre 2006 e 2016, a cobertura de mangue do município de Roteiro apresentou, em 2006, uma área de 11,5 km², distribuída em grandes manchas próximas à lagoa do Roteiro. Em 2016, o mangue apresentou uma expansão de, aproximadamente, $5.8 \mathrm{~km}^{2}$ (Figura 2).

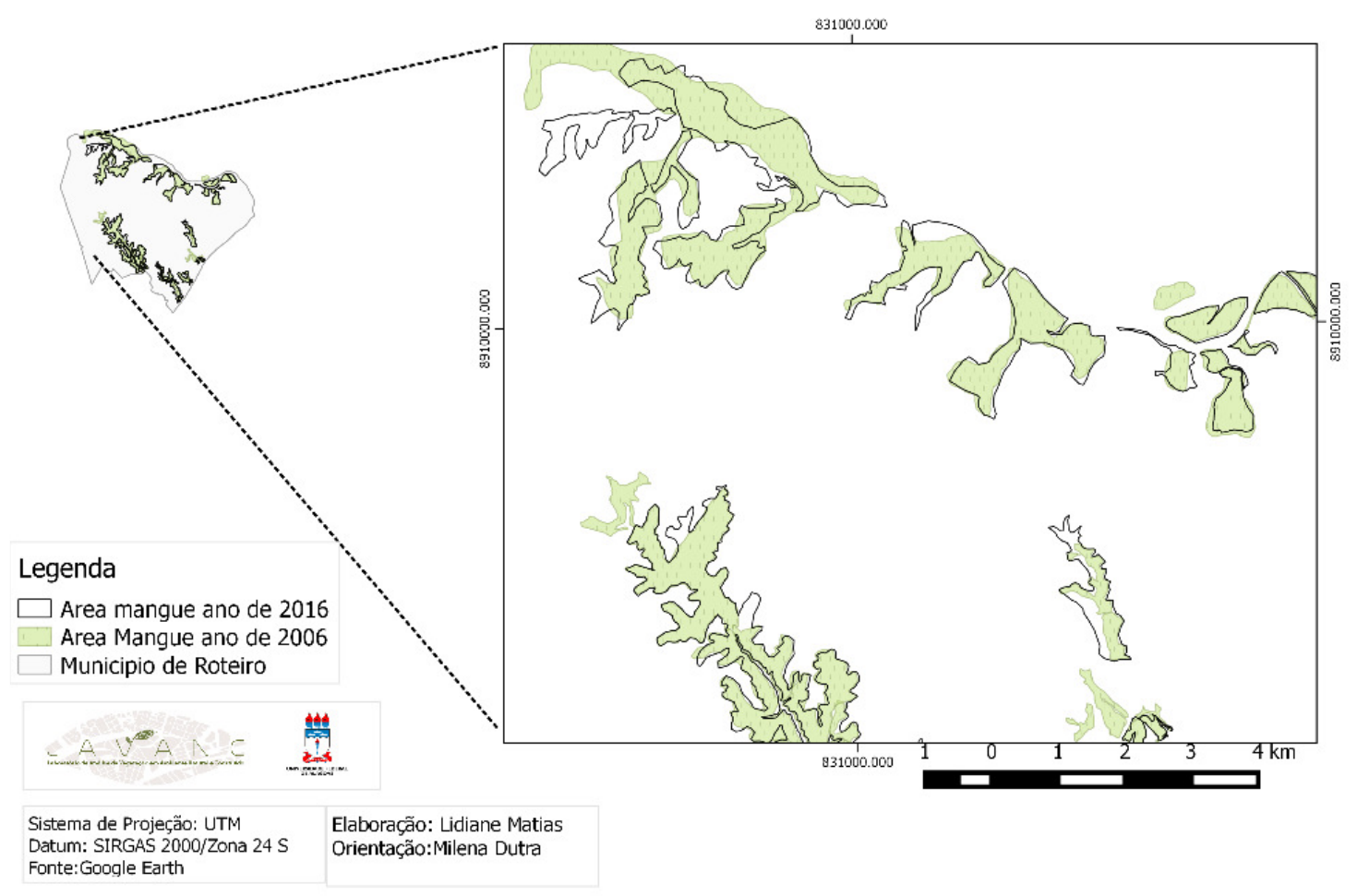

Figura 2. Cobertura de mangue nos anos de 2006 e 2016 em Roteiro, Alagoas, Brasil.

Assim, consideram-se áreas fragilizadas aquelas manchas de vegetação dispostas em "ilhas", fragmentadas, e que ao longo dos anos tenderam a redução, chegando ao desaparecimento.

\section{Resultados}

Os resultados obtidos apontam alterações na paisagem ocorridas no solo do litoral sul de Alagoas, com enfoque no ecossistema manguezal entre as décadas de 2000 e meados da década de 2010 (Tabela 1).

Tabela 1. Áreas com cobertura de mangue no litoral sul de Alagoas, Brasil, nos períodos entre os anos de 2004-2006 e 2016.

\begin{tabular}{lcc}
\hline Municípios & $\mathbf{2 0 0 4 - 2 0 0 6}$ & $\mathbf{2 0 1 6}$ \\
\hline & & Ârea $\left(\mathbf{k m}^{2}\right)$ \\
\hline Roteiro & 11,5 & 17,3 \\
\hline
\end{tabular}

\begin{tabular}{lll}
\hline Jequiá da Praia & $2,83 *$ & 3,95 \\
\hline Coruripe & 2,74 & 2,59 \\
\hline Piaçabuçu & 0,30 & 0,39 \\
\hline
\end{tabular}

*Cobertura de mangue apenas em 2004.

Embora o mangue em Roteiro tenha se expandido entre as décadas de 2000 e 2010 , as manchas maiores, identificadas em 2006, com o passar dos anos, foram fragmentadas e, outras manchas menores e mais isoladas, se extinguiram (Figura 2). Observou-se, ainda, que manchas menores e próximas tenderam a se unir.

No Município de Piaçabuçu, os resultados obtidos na identificação e mapeamento de áreas de manguezal apontam que, no ano de 2006, o mangue apresentava uma cobertura de, aproximadamente, $0,3 \mathrm{~km}^{2}$, disposto em manchas isoladas e de forma fragmentada (Figura 3.) 


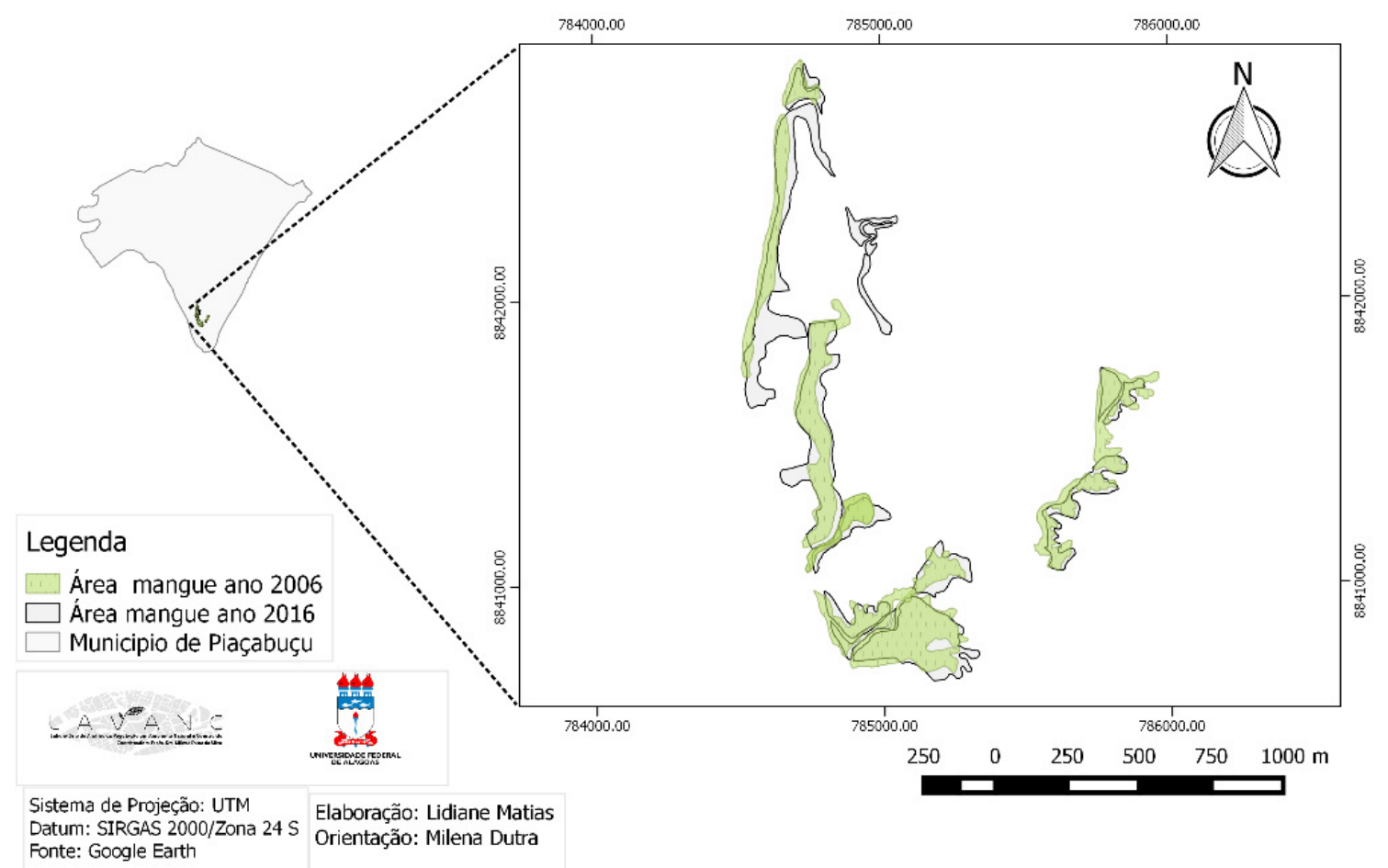

Figura 3. Cobertura de mangue nos anos de 2006 e 2016 em Piaçabuçu, Alagoas, Brasil.

Em análise comparativa entre os anos de 2006 e 2016, observa-se que a área total de cobertura de mangue apresentou um acréscimo de aproximadamente $0,09 \mathrm{~km}^{2}$ nessa mesma área.
Em Jequiá da Praia, ao realizar o mapeamento de mangue correspondente ao ano de 2004, foi possível diagnosticar que o mangue apresentou uma cobertura de 2,67 km² (Figura 4).

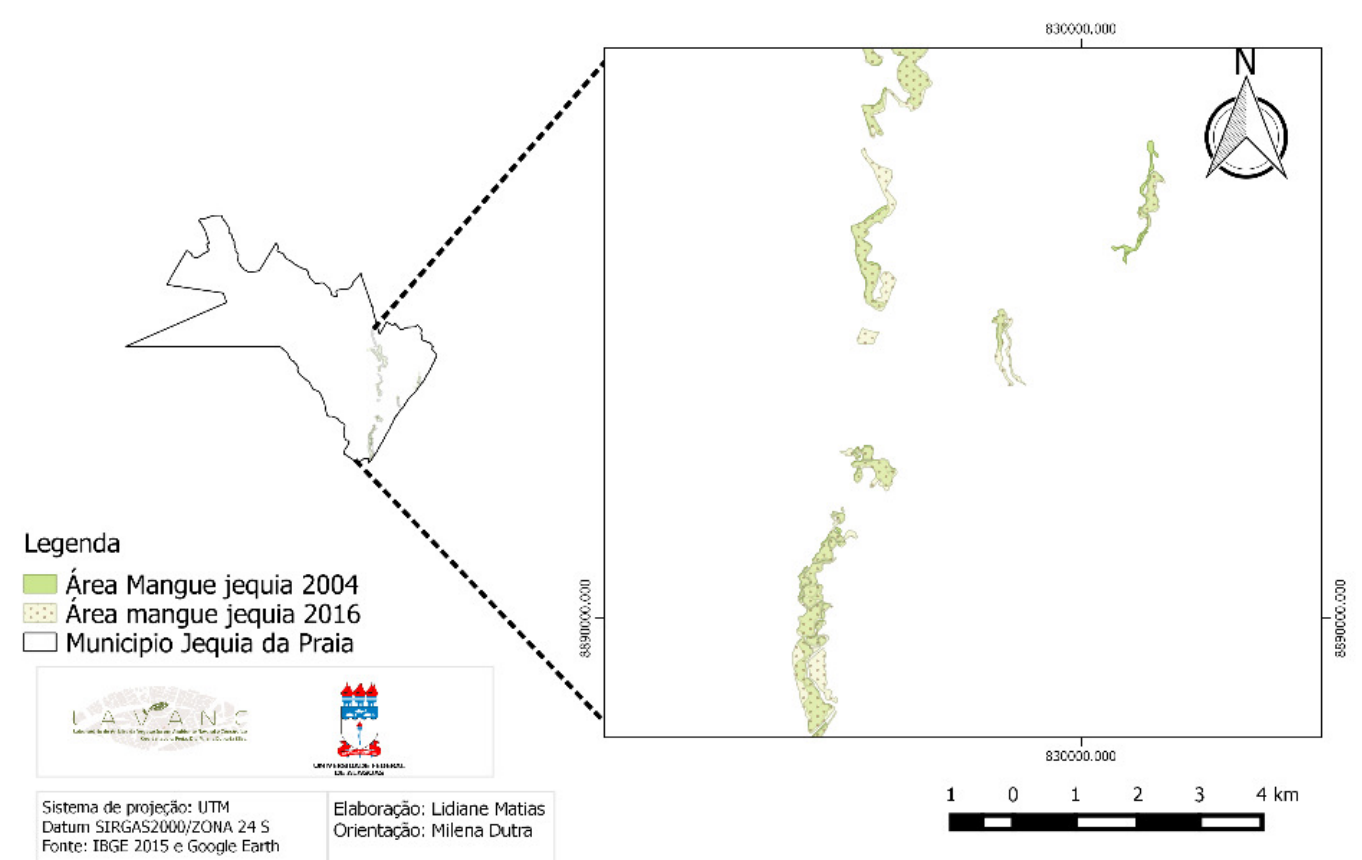

Figura 4. Cobertura de mangue nos anos de 2004 e 2016, em Jequiá da Praia, Alagoas, Brasil.

Em análises comparativas, observando um intervalo de 12 anos, identificou-se um acréscimo de $1,12 \mathrm{~km}^{2}$ na cobertura vegetal, dada pela presença de "novas áreas" de mangue na paisagem.

Entretanto, os fragmentos que eram observados em 2006, de menor área e mais isolados, em 2016, estão ausentes. Essa supressão, aparentemente, decorre da alta fragilidade ambiental dos fragmentos somados às atividades humanas e mudanças físicas (quer naturais e/ou antrópicas).

As manchas com mangue, analisadas no mês de maio de 2004, em Jequiá da Praia, 
apresentam forma linear e estão próximas entre si. Essas manchas, ao longo dos anos, se uniram formando manchas maiores; entretanto, manchas menores e mais isoladas foram suprimidas da paisagem e substituídas pela monocultura de coco.
No município de Coruripe, diferentemente dos outros municípios no litoral sul, houve uma redução da vegetação de mangue entre as décadas de 2000 e 2010, correspondente a um decréscimo de $0,15 \mathrm{~km}^{2}$ (Figura 5).

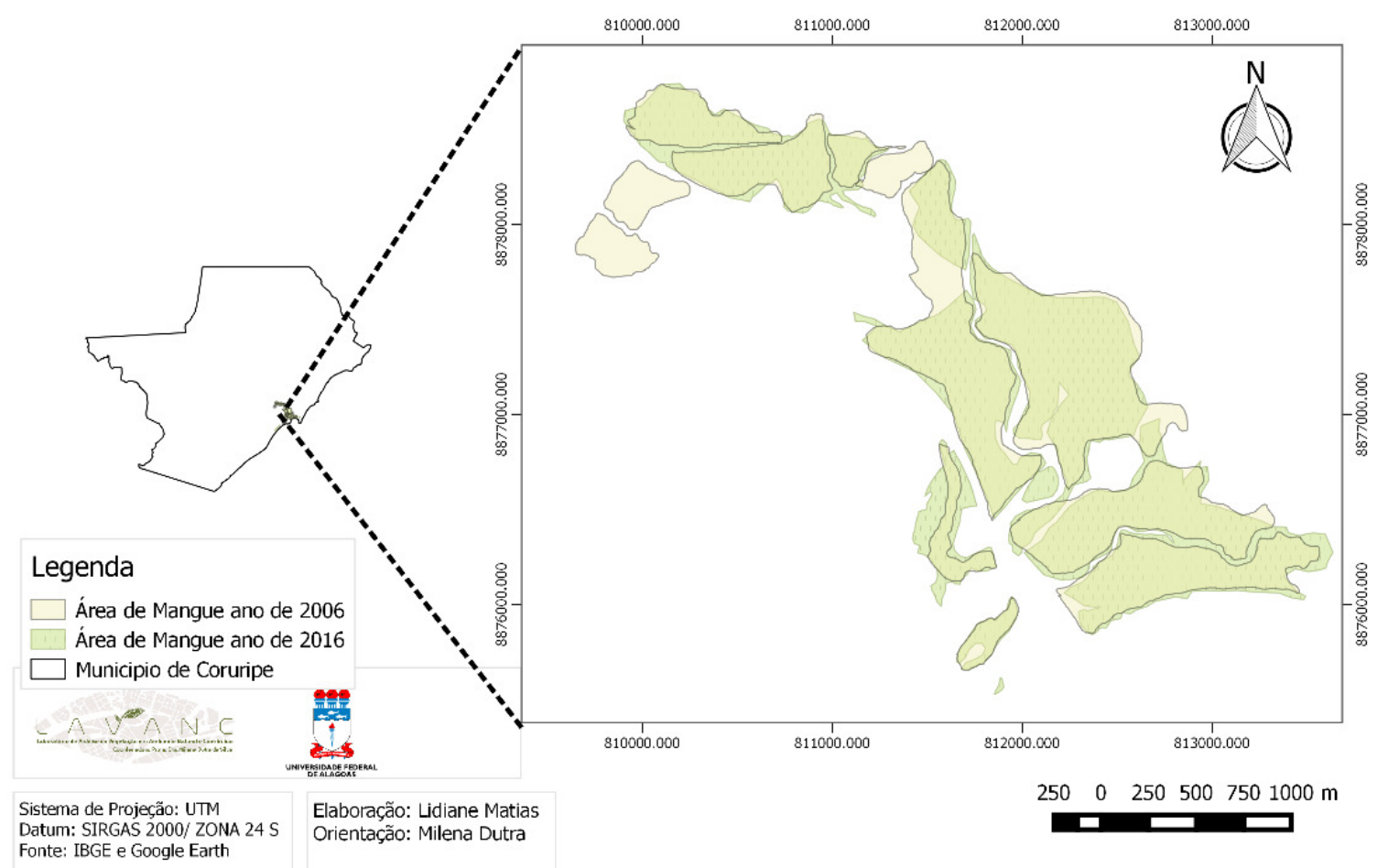

Figura 5. Cobertura de mangue nos anos de 2006 e 2016, em Coruripe, Alagoas, Brasil.

Fragmentos de mangue menores, mais próximos entre si, se uniram, enquanto as mais isoladas foram extintas com o passar dos anos. As reduções de algumas áreas aparentemente podem estar relacionadas à implantação de ocupações urbanas, e agricultura.

\section{Discussão}

$\mathrm{O}$ mangue tem a sua abrangência territorial (redução ou expansão) condicionada, também, por fatores abióticos, que o afetam e o regulam, a exemplo da variação do nível do mar, que pode provocar a supressão da vegetação ou o avanço da mesma em direção à linha da costa (Novelli et al., 2015).

Nos municípios de Roteiro e Jequiá da Praia, devido ao fato de existirem grandes regiões estuarino-lagunares, os ecossistemas manguezais ocupam áreas bastante significativas, principalmente ao longo dos canais, enquanto em Feliz Deserto e Piaçabuçu, os manguezais apresentam áreas menores, pois os rios que deságuam neste litoral apresentam menor volume de águas e consequentemente também menores áreas estuarinas (Correia \& Sovierzoski, 2008).
Embora tenha-se diagnosticado uma redução da área total de mangue em Coruripe, observou-se uma expansão em alguns pontos, principalmente em áreas próximas as margens de lagoas. Em verificação em campo observou-se que áreas de expansão correspondiam a indivíduos jovens de Avicennia schaueriana, com altura média entre $30 \mathrm{~cm}$ e $1,50 \mathrm{~m}$.

Em Roteiro, por ser considerado um dos municípios do estado de Alagoas com maiores áreas de cobertura de mangue, são praticadas medidas de proteção ambiental, a exemplo da Reserva Ecológica de Manguezais da Lagoa do Roteiro (RESEC da Lagoa do Roteiro), criada pelo Decreto ${ }^{\circ} 32.355 / 1987$, para a conservação da extensa área de manguezal que constitui um importante reduto de renovação e manutenção dos estoques pesqueiros da região, sendo a lagoa do Roteiro a quarta em extensão no estado (Correia \& Sovierzoski, 2008).

Em Piaçabuçu a supressão da vegetação de mangue, aparentemente, decorre da alta fragilidade ambiental dos fragmentos somados às atividades humanas e mudanças físicas (quer naturais e/ou antrópicas). 
Em uma outra análise, essa expansão pode decorrer do represamento do Rio são Francisco, e aumento da salinidade das águas como consequência da maior entrada de água salina, favorecendo o desenvolvimento da vegetação.

No município de Jequiá da Praia a expansão da cobertura de mangue pode ser justificada pela criação da Reserva Extrativista Marinha de Jequiá da Praia (RESEX de Jequiá da Praia), criada em 27 de dezembro de 2011 pelo Decreto Federal s/no, que tem como objetivo proteger o uso sustentável e a conservação dos recursos naturais renováveis, sendo assim protegendo os meios de vida e a cultura da população extrativista local. Tal medida de proteção ambiental pode propiciar a expansão de áreas de mangue.

Acrescenta-se, ainda, para interpretação da dinâmica espaço-temporal do mangue no litoral sul alagoano, as grandes temporadas de estiagem, acarretando a redução da entrada de águas doces no sistema, diminuição da vazão de rios, e aumento de águas salinas nesses ambientes, favorecendo o desenvolvimento de vegetação tolerante à alta salinidade.

Conforme Santana (2011), a expansão de mangue pode ser atribuída aos longos períodos de seca que essa região do Nordeste passa durante o ano e ao elevado grau de represamento dos rios nessa região, que contribui para diminuição do fluxo de água doce consequentemente permite uma maior entrada de agua salina nos estuários.

Por outro lado, a redução dessas áreas no litoral Sul Alagoano pode ser atribuída a extração desordenada de madeira, aterros principalmente para o turismo que se expandiu muito na região e crescimento urbano além da agricultura de cana de açúcar. De acordo com Maia (2005), O aumento ou decréscimo das áreas de mangues pode ser usado como indicador de mudanças climáticas de processos antrópicos, associados ao uso dos recursos hídricos e do solo.

Em Coruripe, a expansão do mangue nas margens de lagoas é compatível com o aumento de atividades de fiscalização e proteção ambiental desse ecossistema, promovidas pelo governo municipal. Frente às reduções de áreas de mangue surgem medidas para a promoção da recuperação do manguezal, a exemplo de ações desenvolvidas pelo movimento Eco Mangue Coruripe, uma organização não governamental sem fins lucrativos, fundada em 2012 por moradores, que tem como objetivo promover a conservação da diversidade biológica e cultural do Ecossistema manguezal e do Rio Coruripe, assim como promover a educação e o conhecimento para conservar esse ecossistema.
A mudança ao longo dos anos da vegetação de mangue no litoral Alagoano, assim como de outros ecossistemas, está relacionada com os impactados antrópicos, devido principalmente ao cultivo de coco e à instalação das vilas, posteriormente transformadas em cidades (Correia \& Sovierzoski 2008).

\section{Conclusão}

Foi evidente a ocorrência de uma grande expansão da área de mangue nos municípios de Roteiro, Jequiá da Praia e Piaçabuçu. Entretanto, o município de Coruripe apresentou um decréscimo em comparação com a área analisada no período anterior. Acredita-se que a expansão dessa vegetação está relacionada às unidades de conservação presentes nos municípios, bem como aos fatores e processos atuantes nesse ecossistema.

\section{Agradecimentos}

Os autores agradecem ao Laboratório de Ambiente Natural e Construído (LAVANC) da Universidade Federal de Alagoas, pelo suporte oferecidos durante a realização do estudo.

\section{Referencias}

ARAÚJO, T. C. M.; SANTOS, R. C. DE A. L.; SEOANE, J. C. S.; SEOANE, V. DO A. V. 2000. Erosão e progradação do litoral brasileiro I alagoas. Disponível em: http://www.mma.gov.br/estruturas/sqa_sigercom/ arquivos/al_erosao.pdf. Acesso em: 22 de jna. de 2017.

CASASCO, B.; SANTOS, C.; QUIÑONES, E. 2014. Recuperação de manguezais brasileiros; Universidade Santa Cecília/2009-2014. Revista Ceciliana, v. 6, n. 1, p. 1-5.

CORREIA, M. D.; SOVIERSOSKI, H. H. 2005. Ecossistemas Marinhos: recifes, praias e manguezais. 2005. 55p. Disponível em: http://www.ufal.edu.br/usinaciencia/multimidia/li vros-digitais-cadernos-tematicos. Acesso em: 14 de nov. de 2016.

CORREIA. M. D.; SOVIERSOSKI, H. H. 2008. Gestão e Desenvolvimento Sustentável da Zona Costeira do Estado de Alagoas, Brasil. Revista da Gestão Costeira Integrada, v. 82, p. 25-45.

DANTAS, M. J. F; OLIVEIRA, F. G; ARRAES, F. D. D.; SANTOS. J. B.; ZIMBACK, C. R. L. 2009. Dinâmica espaço-temporal da vegetação no semiárido Cearense/Brasil. 
FLORENZANO, T. G. 2002. Imagens de satélite para estudos ambientais. São Paulo: Oficina de Textos. 97p.

KRUG, L. A; LEÃO, C.; AMARAL, S.; 2007 Dinâmica espaço-temporal de manguezais no Complexo Estuarino de Paranaguá e relação entre decréscimo de áreas de manguezal e dados socioeconômicos da região urbana do município de Paranaguá-Paraná. Florianópolis, Brasil, 21-26 abril 2007, INPE, pp. 2753-2760.

LACERDA, L. D. 1984. Manguezais: florestas de Beira-mar. Ciência Hoje, v. 3, n. 13, p. 63-70.

LEITE, A. C. S.; SENA, F. T. N. S.; NETO, B. J. $S ;$ 2012. Técnicas de sensoriamento remoto na análise temporal para a gestão territorial do município de Timon-MA. Recife-PE.

MAIA, L. P.; LACERDA, L. D.; MONTEIRO, L. H. U.; SOUZA, G. M.; 2007. Estudo das áreas de manguezais do nordeste do Brasil. Fortaleza, Ceará / novembro de 2005. Mangue no bairro de São Domingos em Ilhéus-BA: Paisagem Ambiente: Ensaios, n. 24, p. 39-48.

NANNI, H. C.; NANNI, S. M.; SIGNINI, R. C. 2005. A importância dos manguezais para o equilíbrio ambiental. II simpósio internacional de ciências integradas Da UNAERP campus Guarujá.

NOVELLI, Y. 1999. Grupo de ecossistema: Manguezal, marisma e apicum, São Paulo. Disponível em: http://www.brazilrounds.gov.br/round7/arquivos_
r7/SISMICA R7/refere/manguezal marisma apic um.pdf. Acesso: 11 de dezembro de 2016.

NOVELLI, Y. S. 1995. Manguezal: Ecossistema entre a terra e o mar; Carribbean Ecological Research. São Paulo. 64p.

NOVELLI, Y. S. VALE, CC., and CINTRÓN, G. 2015. Monitoramento do ecossistema manguezal: estrutura e características funcionais. In: TURRA, A.; DENADAI, M. R. Orgs. Protocolos para o monitoramento de habitats bentônicos costeiros Rede de Monitoramento de Habitat Bentônicos Costeiros-ReBentos [online]. São Paulo: Instituto Oceanográfico da Universidade de São Paulo, pp. 62-80.

OLIVEIRA, O. M. G.; CUNHA, R. D. A. 2007. O SIG como ferramenta de análise da paisagem: o caso do mangue no bairro de São Domingos em Ilhéus-BA. Paisagem Ambiente: ensaios, n. 24.

SANTANA, N. M. G.; GALVINCIO, J. D.; TORRES, M. F. A.; PASSOS, P. F.; SILVA, C. A. V.; SILVA, H. A.; CAVALCANTE, E. R. A.; TEIXEIRA, J. L.; PAZ, D. M.; SILVA, J. B.; LIRA, D. R. 2011. Distribuição Espaço Temporal do Ecossistema Manguezal no Estuário Do Rio Itapessoca-Goiana/PE. Curitiba, PR, Brasil, 30 de abril a 05 de maio de 2011, INPE. pp. 6826.

SANTOS, F. 2011. Uso de geotecnologias para mapeamento de manguezais. Boletim Científico ESMPU, Brasília. 